\title{
Periódicos científicos das Ciências Agrárias: análise dos títulos brasileiros indexados na Web of Science e Scopus
}

\begin{abstract}
Aline Borges de Oliveira
\end{abstract}
\author{
Doutoranda em Ciência da Informação na \\ Universidad Complutense de Madrid. Bolsista \\ CAPES
}

Rosângela Schwarz Rodrigues

Professora do Programa de Pós-Graduação em Ciência da Informação da Universidade Federal de Santa Catarina. Bolsista de Produtividade 2 CNPq

Márcio Matias

Professor do Programa de Pós-Graduação em Ciência da Informação da Universidade Federal de Santa Catarina

http://dx.doi.org/10.1590/1981-5344/2582

Esta pesquisa estuda as características dos periódicos brasileiros da grande área das Ciências Agrárias indexados na Web of Science e Scopus. Os objetivos específicos são: a) Identificar os periódicos brasileiros da grande área das Ciências Agrárias definidos pela CAPES; b) Descrever as características dos periódicos: ano de criação; entidade editora; indicadores de qualidade; idiomas aceitos; periodicidade; plataformas; identificador persistente; e c) Identificar o patrocínio e o modelo de financiamento dos periódicos. A metodologia utilizada para a pesquisa caracteriza-se como bibliográfica, documental, descritiva e exploratória, com análise qualiquantitativa. O resultado identificou 74 revistas, 71 em acesso aberto e três por subscrição. Todas as 74 revistas estão indexadas na Scopus e 44 em conjunto entre a Scopus e WoS. As principais entidades editoriais são as universidades, que mantêm 50\% das revistas, seguidas das associações com $32,4 \%$, institutos de pesquisa com $13,5 \%$, e uma editora comercial com $4,1 \%$. Verifica-se que nenhuma revista é Qualis $A 1$ e a predominância dos títulos estão no estrato $B 1$, com $43,2 \%$ (32) revistas. Quanto ao modelo de financiamento, 56,8\% (42) revistas adotam a via dourada, 29,7\% (32) dos títulos seguem a via platina e $4 \%$ subscrição. 
Palavras-chave: Comunicação Científica; Periódicos científicos brasileiros; Ciências agrárias.

\section{Journals scientific of Agrarian Sciences: analysis of the Brazilian titles indexd in the Web of Science and Scopus}

This research studies the characteristics of the $p$ journals Brazilians of the large area of Agrarian Sciences indexed in the Web of specific objective Science and Scopus. The specific objectives are: a) To identify the journals Brazilians of the large area of Agrarian Sciences defined by the CAPES; b) To describe the characteristics of the journals ones: year of creation; entity publishing company; quality indicators; accepted idioms; regularity; platforms; persistent identification; e c) To identify to the sponsorship and the model of financing of the journals ones. The methodology used for the research is characterized as bibliographical, documental, descriptive and exploratória, with quali-quantitative analysis. The corpus of the study is journals the scientific Brazilians registered in the WebQualis of the large area of Agrarian Sciences, defined for the CAPES and indexd in the WoS and resulted Scopus. O it identified 74 you search, 71 in open access and three for subscription. All the 74 periodic are indexed in the Scopus and 44 together between the Scopus and WoS . The main publishing entities are the universities, which maintain $50 \%$ (37) of journals, resulted from the associations with 32,4\% (24), institutes of inquiry with 13,5 \% (10), and a commercial publisher with 4,1\% (3). One checks that no journals is a Qualis $A 1$ and the predominance of the titles they are in the stratum B1, with 43,2 \% (32) you search. As for the financing model, 56,8\% (42) journals adopt the golden road and $29,7 \%$ (32) of the titles follow the Platine road.

Keywords: Scientific communication; Brazilian scientific journals; Agrarian sciences.

Recebido em 20.10.2015 Aceito em 08.05.2017

\section{Introdução}

As publicações científicas são utilizadas como indicador de desempenho das áreas do conhecimento, pesquisadores ou países e são medidas conforme a quantidade e visibilidade da produção por meio das citações que os trabalhos recebem. Essa visibilidade é calculada a partir 
das citações de artigos para aferir o fator de impacto das revistas científicas e o grau de importância de cada autor. Como consequência, a análise de citações floresceu ao longo das últimas quatro décadas (GARFIELD, 2006) e o fator de impacto tornou-se uma ferramenta estabelecida e amplamente praticada, principalmente para tomadas de decisões políticas, pois assim basea-se em evidências (LÓPEZ-ILLESCAS; MOYA-ANEGÓN; MOEDB, 2008).

A discussão proposta nesta pesquisa visa aprofundar o conhecimento acerca do modelo de publicação e financiamento dos periódicos científicos das Ciências Agrárias indexados na WoS e na Scopus, englobando as subáreas definidas pelo documento de área da Coordenação de Aperfeiçoamento de Pessoal de Nível Superior (CAPES): a) Ciência de Alimentos; b) Ciências Agrárias I; c) Medicina Veterinária; e d) Zootecnia/Recursos Pesqueiros.

A agricultura e agronegócio têm no Brasil papel crucial na economia. O Produto Interno Bruto (PIB) do agronegócio inclui todas as atividades de produção agrícola, as indústrias a montante (máquinas e implementos agrícolas, insumos químicos e biológicos, serviços técnicos especializados, defensivos agrícolas, fertilizantes, entre outras) e as indústrias a jusante (indústrias processadoras, distribuição, comercialização etc.) (FUNDAÇÃo DE AMPARO À PESQUISA DO ESTADO DE SÃO PAULO - FAPESP, 2010a).

O objetivo geral desta pesquisa é estudar as características dos periódicos científicos das Ciências Agrárias no Brasil indexadas na WoS e Scopus. Os objetivos específicos são: a) Identificar os títulos brasileiros definidos pela CAPES; b) Descrever as características dos periódicos: ano de criação; entidade editora; indicadores de qualidade; idiomas aceitos; periodicidade; plataformas; identificador persistente; e c) Identificar o patrocínio e o modelo de financiamento dos periódicos.

\section{Comunicação científica}

A comunicação da ciência se estabelece como meio fundamental no processo de difundir as pesquisas aos públicos específicos. A ciência é feita e disseminada por meio da comunidade, responsável pelo surgimento dos primeiros periódicos científicos (PRICE, 1976). Essa comunidade é constituída por redes de organizações científicas e relações sociais. $O$ principal objetivo das comunidades científicas é assegurar a troca de informações sobre os trabalhos em andamento, colocar os cientistas em contato entre si (LE COADIC, 2004) e facilitar a difusão do conhecimento entre a sociedade e o público em geral (BÖRJK, 2007).

A ciência se configura como um amplo sistema social, onde uma das suas funções é disseminar resultados de pesquisa, assegurar a preservação de padrões e atribuir créditos e reconhecimento para aqueles cujos trabalhos têm contribuído para o desenvolvimento das pesquisas científicas (MACIAS-CHAPULA, 1998; SCHWARTZMAN, 2001). Os mais altos status são conferidos aos cientistas posicionados nas elites científicas e a forma de posicionamento entre a elite científica de pesquisadores se dá pela quantidade e qualidade de suas publicações, que permitem 
identificar a qualidade e velocidade da comunicação do campo e são a memória coletiva da área.

Nos periódicos científicos os autores publicam textos e registram os resultados das pesquisas, legitimando disciplinas e campos de estudos, veiculando a comunicação entre os cientistas e propiciando ao cientista o reconhecimento público da teoria ou da descoberta (FREITAS, 2006). Considerando que o principal papel de uma revista é armazenar os registros de invenções e inovações científicas (GUÉDON, 2001).

Dessa forma, ao longo do tempo, a revista científica se estabeleceu como o principal marco da estrutura da comunicação científica como a conhecemos hoje, destacando-se como principal meio de divulgação das informações científicas (WEITZEL, 2006; WITTER, 2011). Esse destaque fez com que o número de revistas apresentasse rápido crescimento, principalmente após a Segunda Guerra Mundial, momento que marcou o nascimento de um mercado internacional para as publicações científicas (GUÉDON, 2010).

Com o advento das redes, em especial a Internet, e a ascensão das publicações digitalizadas com a migração em massa das revistas impressas para o formato eletrônico, pode-se contar com uma variedade de estratégias de publicação e oferecer aos leitores facilidade especial de acesso (GUÉDON, 2001; WILLINSKY, 2003; SILVA; SANTOS; PRAZERES, 2011).

O formato digital das revistas científicas trouxe novas funcionalidades para recuperar e disseminar as informações, criando novas ferramentas e tornando o processo editorial mais complexo e sofisticado, exigindo profissionais especializados e novas estratégias. Nesse contexto está o acesso aberto, que se apresenta como uma alternativa em resposta às restrições de acesso à informação científica. Na próxima seção, apresentam-se os modelos de financiamento para os periódicos científicos e suas particularidades.

\subsection{Modelos de financiamento dos periódicos científicos}

Segundo Mueller (2011) a migração para o meio digital não significa a inexistência de custos. Atualmente, existem revistas que se encontram no modelo conhecido como tradicional, com o acesso somente por meio de subscrição e aquelas em acesso aberto, pagos pelo autor ou pela instituição editora (BJÖRK, 2007), conforme mostra o Quadro 1:

Quadro 1 - Modelos de financiamento para periódicos científicos

\begin{tabular}{l|l}
\hline & $\begin{array}{l}\text { Acesso livre para todos. Nesse caso os custos são } \\
\text { Via Platina }\end{array}$ \\
integralmente assumidos pela entidade editora do \\
conteúdo que pode ser: faculdades e departamentos \\
universitários, associação científica, centros de \\
investigação ou outro organismo público. \\
\hline Via Dourada & Pagamento de taxa para submissão ou publicação (pelo \\
\hline
\end{tabular}




\begin{tabular}{l|l}
\hline & $\begin{array}{l}\text { autor): neste caso, não há financiamento público ou } \\
\text { patrocínio, o custo é de responsabilidade do autor, ou de } \\
\text { sua instituição ou projeto de pesquisa. }\end{array}$ \\
\hline Subscrição & $\begin{array}{l}\text { É semelhante ao caso anterior (o autor paga) e a diferença } \\
\text { é que os artigos aceitos pelas revistas comerciais se } \\
\text { com opção de } \\
\text { acesso aberto }\end{array}$ \\
encontram nas duas opções: abertos e fechados, dentro da \\
mesma publicação. Nesse caso, para publicar o artigo em \\
acesso aberto, a editora cobra do autor.
\end{tabular}

Fonte: Adaptado de MELERO; ABAD-GARCÍA (2008); NETWORK OF COLLABORATION BETWEEN EUROPE AND LATIN AMERICA AND CARIBBEAN COUNTRIES (2011); ABADAL (2012).

Para os casos de revistas com subscrição há ainda a opção de embargo, onde depois de um tempo que varia de 6 a 24 meses colocam os fascículos completos em Acesso Aberto. Para este caso quem possui os direitos autorais são os editores e não os autores, para áreas com rápida obsolescência o ganho é limitado.

Para o caso da Via Platina, o acesso é livre e gratuito aos leitores e autores. Enquanto que na Via Dourada, existem as taxas de processamento por artigo ou Article Processing Charge (APC), que se refere às taxas de submissão e ou publicação, cobradas aos autores ou suas instituições a fim de subsidiar os custos das revistas de acesso aberto (CROW, 2009; SOLOMON; BJORK, 2012).

O surgimento das bases de dados está diretamente relacionado à necessidade do controle, da disseminação e da visibilidade dos registros do conhecimento científico produzido pelas comunidades científicas. Os elementos que caracterizam uma base de dados são: a) constituição de um repositório para armazenamento de grandes volumes organizados de informações variadas; b) as informações são armazenadas em suporte, seja magnético ou óptico e acessadas via computadores; c) utilização de um programa de gerenciamento das informações armazenadas visando a rápida e precisa recuperação (SILVA; RAMOS; NORONHA, 2006). As bases de dados em conjunto com as revistas científicas, são as principais protagonistas da comunicação científica (MIGUEL; CHINCHILLARODRÍGUEZ; MOYA-ANEGÓN, 2011).

As fontes de informações de citações com maior prestígio internacional são a Web of Science (WoS) e a Scopus, utilizadas para a seleção das revistas desta pesquisa. A WoS é uma fonte multidisciplinar de resumos (e citações que indexa artigos de periódicos mais citados. A ferramenta utilizada para a coleta dos dados desta pesquisa é o Journal Citation Reports (JCR) criado nos anos de 1960 e foi a primeira publicação deste gênero, sendo que por meio do cálculo de citações, permitiu identificar os artigos mais citados Dessa forma, foi possível identificar os trabalhos mais procurados pela comunidade científica (GUÉDON, 2010; CORREIA; MESQUITA, 2013).

A ferramenta desenvolvida pela Scopus para se calcular o fator de impacto é - SClmago Journal Rank (SJR), criado pela SClmago. Essa ferramenta está 
disponível gratuitamente e inclui indicadores científicos de publicações periódicas e países, desenvolvidos a partir da informação da base de dados Scopus, produzida pela editora Elsevier. A métrica SJR baseia-se no algoritmo do Google PageRank, que mostra a visibilidade dos títulos de periódicos indexados na base de dados Scopus desde 1996 (CORREIA; MESQUITA, 2013). Os fatores de impacto da WoS e Scopus são os indicadores mais utilizados para a classificação e comparação das revistas no meio acadêmico (ABRIZAH et al., 2013a).

A limitação da WoS e Scopus quanto ao numero de títulos indexados levou a criação de novos indicadores que abrangem mais revistas. Nesta pesquisa utilizou-se o índice h5 do Google Scholar Metrics (GSM), ferramenta desenvolvida pelo Google Scholar, um dos serviços disponibilizados pela empresa que desenvolveu o motor de pesquisa Google. Essa ferramenta lista 8 áreas do conhecimento definidas pelo Google Scholar e ainda, as 100 melhores revistas em nove idiomas (Inglês, Chinês, Português, Alemão, Espanhol, Francês, Italiano, Japonês e Holandês) e os seus respectivos índices h5. O índice h5 é o índice h calculado utilizando somente os artigos publicados nos últimos cinco anos. (DELGADO-LÓPEZ-CÓZAR; CABEZAS-CLAVIJO， 2012-2013; GOOGLE SCHOLAR, 2014).

Toda a produção científica brasileira é avaliada pela CAPES por meio de critérios específicos para cada área. Dessa forma, a CAPES criou o Qualis, que conceitua a produção intelectual dos pesquisadores do Brasil, tendo a sua primeira aplicação no triênio 1998 e 2000. Conforme explica a Coordenação de Aperfeiçoamento de Pessoal de Nível Superior (CAPES, 2004 , p. 1) o Qualis é uma "classificação de veículos de divulgação da produção intelectual (bibliográfica) dos programas de pós-graduação stricto sensu utilizada pela CAPES para a fundamentação do processo de avaliação da pós-graduação nacional por ela promovido".

No Brasil as principais agências de fomento, Conselho Nacional de Desenvolvimento Científico e Tecnológico (CNPq) e CAPES, utilizam o Qualis, que é baseado principalmente no JCR da WoS e no SJR da Scopus, para avaliar a produção científica das universidades, institutos de pesquisas, pesquisadores e também das revistas científicas que são indexadas nessas duas fontes de informações.

No Brasil, a área Ciências Agrárias se tornou uma das mais eficientes e sustentáveis, apresentando padrão internacional de publicações científicas (EMPRESA BRASILEIRA DE PESQUISA AGROPECUÁRIA - EMBRAPA, 2014a). Isso se deu por meio do desenvolvimento do sistema de pesquisa composto pela Embrapa, por instituições estaduais, pelas universidades e mais recentemente, por instituições privadas (BUAINAIN et al., 2014).

Conforme a CAPES (2014), com o intuito de facilitar a avaliação, as 48 áreas são agregadas por critério de afinidade em dois níveis, sendo distribuídas posteriormente em 3 Colégios e 9 Grandes Áreas. Os níveis são os seguintes: a) Primeiro nível: Colégios: e b) Segundo nível: Grandes Áreas. Dessa forma, a grande área das Ciências Agrárias se insere no Colégio de Ciências da Vida, sendo divido em 4 áreas, composta pelas 
áreas: a) Ciência de Alimentos; b) Ciências Agrárias I; c) Medicina Veterinária; e d) Zootecnia/Recursos Pesqueiros.

\section{Metodologia}

Quanto aos procedimentos técnicos, esta pesquisa caracteriza-se como bibliográfica e documental. Para o tratamento dos dados foi utilizado estatística descritiva e exploratória e quanto à abordagem, se classifica como quali-quantitativa (VAUGHAN, 2008; CONNAWAY; POWELL, 2010; CRESWELL, 2010). As revistas que fazem parte do corpus desta pesquisa estão classificadas dentro de pelo uma das quatro áreas que compõem a grande área das Ciências Agrárias no Brasil, conforme a CAPES: a) Ciência de Alimentos; b) Ciências Agrárias I; c) Medicina Veterinária; e d) Zootecnia/Recursos Pesqueiros (CAPES, 2014). O ponto de partida para a escolha das revistas se deu pela identificação dos títulos que estavam indexados nas bases de dados WoS e Scopus. Essas bases possuem significativa amplitude de periódicos e são consideradas as mais rigorosas na seleção dos títulos, além de indexar as revistas acadêmicas, oferecem recursos bibliométricos para classificar as revistas em termos de produtividade e total de citações recebidas para indicar o impacto das revistas (CHADEGANI et al., 2013). Sendo que se pode considerar que todos os títulos indexados por elas possuem qualidade reconhecida internacionalmente.

Para localizar as revistas optou-se por selecionar as revistas que se enquadram na grande área das Agrárias definidas pela CAPES. Com isso, as revistas que estavam na WoS e Scopus como sendo das Agrárias, mas sem registro no Qualis em nenhuma das 4 áreas registradas pela CAPES não foram incluídas na amostra.

\section{Resultados e discussão}

Do total de periódicos que compõem o corpus desta pesquisa, todos os 74 títulos estão na Scopus e 44 na Scopus e na WoS simultaneamente. A WoS abrange um conjunto mais seletivo de revistas, enquanto que a Scopus apresenta cobertura mais ampla

Dessa forma, conforme Brzezinski (2015), a Scopus é a principal concorrente da WoS. Sendo que "no meio acadêmico é a única que consegue competir com a Web of Science" (PINTO; MATIAS, 2011, p. 7). Isso porque o sistema de seleção da Scopus é menos restritivo do que da WoS (GARFIELD, 2006; LÓPEZ-ILLESCAS; MOYA-ANEGÓN; MOED, 2008; RODRÍGUEZ-YUNTA, 2010).

Do total de 330 revistas brasileiras indexadas na Scopus, 22,4\% pertencem à área das Agrárias. Em relação à WoS, que indexa um total de 165 títulos brasileiros, as revistas das Agrárias do Brasil representam 27\% das revistas que ali são indexadas.

Hoje o Brasil destaca-se por ter aumentado cerca de oito vezes o número de periódicos que são indexados na WoS, desde 2000, e configura, assim, como um dos países emergentes que tem estabelecido 
revistas científicas nacionais como uma rota de publicação alternativa para seus pesquisadores, além de exercer um significativo esforço para aumentar a presença de seus periódicos nas bases internacionais de publicações científicas (MENEGHINI, 2012b, 2014).

\subsection{Características dos periódicos da Agrárias}

Na Tabela 1, apresenta-se a distribuição do ano de criação das revistas. Para identificar o ano, pesquisou-se no site de cada uma delas e quando a informação não constava, acessou-se o site Ulrichs.

Tabela 1 - Ano de criação dos periódicos do corpus desta pesquisa

\begin{tabular}{c|r|r|r|r|r|r}
\hline & Universidades & Associações & $\begin{array}{c}\text { Institutos de } \\
\text { pesquisa }\end{array}$ & Outras & Total & \% \\
\hline \hline 1931 à 1940 & 2 & - & 1 & - & 3 & $4,1 \%$ \\
\hline 1941 à 1950 & 2 & - & 2 & - & 4 & $5,4 \%$ \\
\hline 1951 à 1960 & - & 1 & - & 1 & 2 & $2,7 \%$ \\
\hline 1961 à 1970 & 1 & 4 & 2 & - & 7 & $9,5 \%$ \\
\hline 1971 à 1980 & 10 & 11 & 2 & - & 23 & $31,1 \%$ \\
\hline 1981 à 1990 & 3 & 4 & - & - & 7 & $9,5 \%$ \\
\hline 1991 à 2000 & 8 & - & 2 & 1 & 11 & $14,9 \%$ \\
\hline 2001 à 2010 & 11 & 4 & 1 & 1 & 17 & $23,0 \%$ \\
\hline Total & 37 & 24 & 10 & 3 & 74 & $100,0 \%$ \\
\hline \% & $33,8 \%$ & $32,4 \%$ & $13,5 \%$ & $4,1 \%$ & $100,0 \%$ & \\
\hline
\end{tabular}

Fonte: Dados da pesquisa (2014).

Por meio da Tabela 2, é possível observar que entre os anos de 1971 e $198031,1 \%$ (23) revistas foram criadas. O que demonstra que a área começou a se desenvolver a partir desse período. Nos anos seguintes, o que apresentou maior surgimento foi entre 2001 e 2010, com $17(22,7 \%)$ revistas. Pode-se verificar ainda, que até a década de 1990 $62,2 \%$ (46) dos títulos nasceram no formato impresso e migraram para 0 digital.

Observa-se que as universidades são as que mantêm a mais elevada porcentagem de títulos, com 50\% (37), e em segundo lugar as Associações com 24 (32,4\%) do total de 74 revistas. Em seguida, estão os Institutos de pesquisa com $10(13,5 \%)$ e editora comercial com três $(4,1 \%)$ dos títulos brasileiros na grande área das Ciências Agrárias.

Os resultados encontrados nesta pesquisa, são equivalentes aos identificados por Rodrigues e Oliveira (2012) em estudo dos títulos da América Latina indexados na WoS e Scopus, identificaram que do total de 536 revistas, $45 \%$ eram mantidas por universidades e em segundo lugar, as associações mantinham 34,7\% dos títulos analisados na pesquisa.

A CAPES desenvolveu os critérios Qualis, que é responsável por aferir a qualidade dos periódicos nacionais, essenciais para a avaliação dos Programas de Pós-Graduação. Uma revista pode ser classificada em mais de uma área e apresentar diferentes estratos entre as áreas que a classificam. Optou-se por coletar o estrato em que a revista estava melhor classificada. Na Tabela 2, apresenta-se a distribuição dos estratos Qualis pelas entidades editoras. 
Tabela 2 - Distribuição dos estratos Qualis/ CAPES dos periódicos do corpus desta pesquisa pelas entidades editoras

\begin{tabular}{l|r|r|r|r|r|r}
\hline & Universidades & Associações & $\begin{array}{c}\text { Institutos de } \\
\text { pesquisa }\end{array}$ & Outras & Total & \multicolumn{1}{c}{$\%$} \\
\hline \hline A1 & - & - & - & - & - & - \\
\hline A2 & 3 & 1 & 1 & 1 & $\mathbf{6}$ & $\mathbf{8 , 1 \%}$ \\
\hline B1 & 14 & 15 & 3 & 2 & $\mathbf{3 4}$ & $\mathbf{4 5 , 9 \%}$ \\
\hline B2 & 8 & 4 & 5 & - & $\mathbf{1 7}$ & $\mathbf{2 3 , 0 \%}$ \\
\hline B3 & 5 & 2 & - & - & $\mathbf{7}$ & $\mathbf{9 , 5 \%}$ \\
\hline B4 & 2 & 2 & - & - & $\mathbf{4}$ & $\mathbf{5 , 4 \%}$ \\
\hline B5 & 5 & - & 1 & - & $\mathbf{6}$ & $\mathbf{8 , 1 \%}$ \\
\hline Total & $\mathbf{3 7}$ & $\mathbf{2 4}$ & $\mathbf{1 0}$ & $\mathbf{3}$ & $\mathbf{7 4}$ & $\mathbf{1 0 0 , 0 \%}$ \\
\hline \% & $\mathbf{5 0 , 0 \%}$ & $\mathbf{3 2 , 4 \%}$ & $\mathbf{1 3 , 5 \%}$ & $\mathbf{4 , 1 \%}$ & $\mathbf{1 0 0 \%}$ & \\
\hline
\end{tabular}

Fonte: Dados da pesquisa (2014).

Dos periódicos do corpus desta pesquisa, nenhum título possui a classificação $A 1$, e a predominância dos títulos está no estrato $B 1$, com $43,2 \%$ (32) revistas e no estrato B2 com $21,6 \%$ (16) títulos.

Uma revista pode estar classificada em uma, duas, três ou em todas as quatro áreas. Na Tabela 5 foi considerado o total de títulos de cada área. Para esta pesquisa, foi escolhido apenas o estrato da área em que o título estava melhor classificado.

Os valores dos fatores de impacto do JCR e SJR, levados em consideração para avaliar a qualidade das revistas e eleger os estratos Qualis/CAPES, estão dispostos no Quadro 2, a seguir.

Quadro 2 - Áreas, estratos Qualis, pesos e critérios de avaliação para as quatro áreas que compões a grande área das Ciências Agrárias conforme a CAPES

\begin{tabular}{|c|c|c|c|c|c|}
\hline \multicolumn{2}{|c|}{ Áreas } & \multirow{2}{*}{$\begin{array}{l}\text { Ciências de } \\
\text { Alimentos }\end{array}$} & \multirow{2}{*}{ Ciências Agrárias I } & \multirow{2}{*}{$\begin{array}{c}\text { Medicina } \\
\text { Veterinária }\end{array}$} & \multirow{2}{*}{$\begin{array}{c}\text { Zootecnia / Recursos } \\
\text { Pesqueiros }\end{array}$} \\
\hline Estrato & Peso & & & & \\
\hline A1 & 100 & $\mathrm{JCR} \geq 3,286$ & $\mathrm{JCR} \geq 2,500$ & $\mathrm{JCR} \geq 3,138$ & $\mathrm{JCR} \geq 2,400$ \\
\hline A2 & 85 & $3,285<\mathrm{JCR} \geq 2,446$ & $1,200 \geq \mathrm{JCR} \leq 2,499$ & $\begin{array}{c}3,138<\mathrm{JCR} \geq \\
2,266\end{array}$ & $2,399<\mathrm{JCR} \geq 1,400$ \\
\hline B1 & 70 & $2,445<\mathrm{JCR} \geq 1,289$ & $0,001 \geq \mathrm{JCR} \leq 1,499$ & $\begin{array}{c}2,266<\mathrm{JCR} \geq \\
0,756\end{array}$ & $1,399<\mathrm{JCR} \geq 0,500$ \\
\hline B2 & 55 & $1,288<\mathrm{JCR} \geq 0,522$ & 4 Bases indexadoras & $\begin{array}{c}\text { JCR }<0,756 \text { ou } \\
\text { ser indexado em } \\
4 \text { bases }\end{array}$ & $0,499<\mathrm{JCR} \geq 0,001$ \\
\hline B3 & 40 & $0,521<\mathrm{JCR} \geq 0,000$ & 3 Bases indexadoras & $\begin{array}{c}3 \text { Bases } \\
\text { indexadoras }\end{array}$ & 4 Bases indexadoras \\
\hline B4 & 25 & $\begin{array}{c}\text { SJR }<0,224 \text { ou duas } \\
\text { bases indexadores }\end{array}$ & 2 Bases indexadoras & $\begin{array}{c}3 \text { Bases } \\
\text { indexadoras }\end{array}$ & 3 Bases indexadoras \\
\hline B5 & 10 & 1 Base indexadora & 1 Base indexadora & Sem indexadores & 1 Base indexadora \\
\hline
\end{tabular}

Fonte: Adaptado de CAPES (2013a; 2013b; 2013c; 2013d).

Pode-se verificar que todas as quatro áreas dessa pesquisa utilizam predominantemente o JCR da WoS como base de qualidade para avaliar suas revistas entre os estratos $A 1, A 2$ e $B 1$, confirmando que o fator de 
impacto da WoS, é um dos índices mais importantes na avaliação da produção científica (ABAD, 2009).

Por ordem decrescente do JCR, as Tabelas a seguir apresentam a distribuição das revistas pelos estratos A2, B1, B2, B3, B4 e B5, comparado aos indicadores JCR, SJR, índice h (Scopus) e índice h5 GSM.

$\mathrm{Na}$ Tabela 3, observa-se a distribuição das revistas do estrato A2.

Tabela 3 - Comparação dos índices JCR, SJR, índice h Scopus e índice h5 GSM dos periódicos Qualis A2, do corpus desta pesquisa

\begin{tabular}{|c|c|c|c|c|c|c|c|c|c|}
\hline 递 & 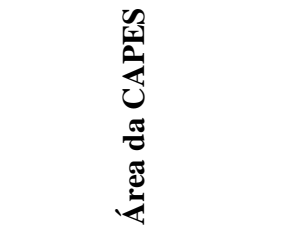 & 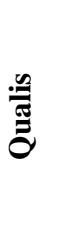 & 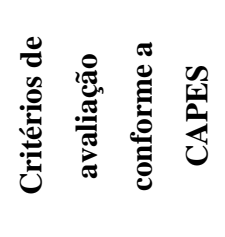 & $\underset{ِ}{\simeq}$ & $\underset{\vec{v}}{\stackrel{\mathscr{V}}{*}}$ & : & 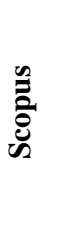 & . & 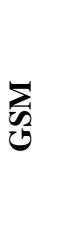 \\
\hline Scientia Agrícola & Ciências Agrárias I & A 2 & $\begin{array}{l}1,200 \geq \mathrm{JCR} \leq \\
2,499\end{array}$ & 0.924 & 0,64 & & 20 & & 18 \\
\hline $\begin{array}{l}\text { Genetics and } \\
\text { Molecular Research }\end{array}$ & Medicina Veterinária & A2 & $\begin{array}{l}3,138<\mathrm{JCR} \geq \\
2,266\end{array}$ & 0.850 & 0,367 & & 28 & & 24 \\
\hline $\begin{array}{l}\text { Pesquisa Agropecuária } \\
\text { Brasileira }\end{array}$ & Ciências Agrárias I & A 2 & $\begin{array}{l}1,200 \geq \mathrm{JCR} \leq \\
2,499\end{array}$ & 0.676 & 0,717 & & 33 & & 21 \\
\hline $\begin{array}{l}\text { Brazilian Journal of } \\
\text { Microbiology }\end{array}$ & Medicina Veterinária & A 2 & $\begin{array}{l}3,138<\mathrm{JCR} \geq \\
2,266\end{array}$ & 0.452 & 0,321 & & 31 & & 20 \\
\hline $\begin{array}{l}\text { Pesquisa Veterinária } \\
\text { Brasileira }\end{array}$ & Medicina Veterinária & A 2 & $\begin{array}{l}3,138<\mathrm{JCR} \geq \\
2,266\end{array}$ & 0,44 & 0,364 & & 21 & & 16 \\
\hline $\begin{array}{l}\text { Arquivo Brasileiro de } \\
\text { Medicina Veterinária e } \\
\text { Zootecnia }\end{array}$ & Medicina Veterinária & $\mathrm{A} 2$ & $\begin{array}{l}3,138<\mathrm{JCR} \geq \\
2,266\end{array}$ & 0,2 & 0,292 & & 18 & & 11 \\
\hline
\end{tabular}

Fonte: Dados da pesquisa (2014).

Conforme se observa na Tabela 3, nenhuma das revistas possui fator de impacto JCR equivalente ao necessário para ser classificada nesse estrato. As revistas que apresentam maiores diferenças entre os fatores de impacto são: a) Scientia Agrícola - 0,924 (JCR) e 0,64 (SJR); b) Genetics and Molecular Research - 0,850 (JCR) e 0,367 (SJR) e c) Arquivo Brasileiro de Medicina Veterinária e Zootecnia - 0,198 (JCR) e 0,292 (SJR). As revistas que apresentam maiores diferenças entre os índices $h$ são: a) Pesquisa Agropecuária Brasileira - índice h (Scopus) 33 e índice h5 21; b) Brazilian Journal of Microbiology- índice h (Scopus) 31 e índice h5 20; ec) Arquivo Brasileiro de Medicina Veterinária e Zootecnia - índice h (Scopus) 18 e índice h5 11.

$\mathrm{Na}$ Tabela 4, observa-se a distribuição das revistas do estrato B1. 
Tabela 4 - Comparação dos índices JCR, SJR, índice h Scopus e índice h5 GSM dos periódicos Qualis B1, do corpus desta pesquisa

\begin{tabular}{|c|c|c|c|c|c|c|c|}
\hline$\frac{\mathscr{0}}{0}$ & 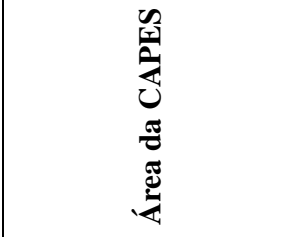 & 层 & 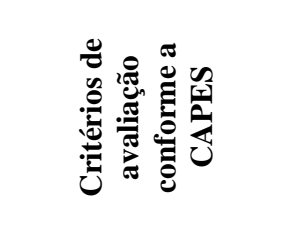 & 气ِ & $\stackrel{\mathscr{v}}{\vec{n}}$ & 导崀 & 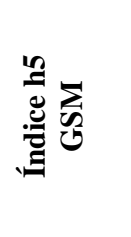 \\
\hline $\begin{array}{l}\text { Revista Brasileira de } \\
\text { Parasitologia } \\
\text { Veterinária }\end{array}$ & Medicina Veterinária & B1 & $2,266<\mathrm{JCR} \geq 0,756$ & 1,11 & 0,419 & 13 & 13 \\
\hline $\begin{array}{l}\text { Brazilian Journal of } \\
\text { Medical and } \\
\text { Biological Research } \\
\end{array}$ & Medicina Veterinária & B1 & $2,266<\mathrm{JCR} \geq 0,756$ & 1034 & 0,431 & 62 & 24 \\
\hline $\begin{array}{l}\text { Genetics and } \\
\text { Molecular Biology }\end{array}$ & Ciências Agrárias I & B1 & $0,001 \geq \mathrm{JCR} \leq 1,499$ & 0,88 & 0,373 & 31 & 15 \\
\hline $\begin{array}{l}\text { Neotropical } \\
\text { Entomology }\end{array}$ & Ciências Agrárias I & B1 & $0,001 \geq \mathrm{JCR} \leq 1,499$ & 0,85 & 0,47 & 27 & 15 \\
\hline $\begin{array}{l}\text { Neotropical } \\
\text { Ichthyology }\end{array}$ & Medicina Veterinária & B1 & $2,266<\mathrm{JCR} \geq 0,756$ & 0,77 & 0,754 & 20 & 15 \\
\hline $\begin{array}{l}\text { Ciência e } \\
\text { Agrotecnologia } \\
\end{array}$ & $\begin{array}{l}\text { Zootecnia / Recursos } \\
\text { Pesqueiros } \\
\end{array}$ & B1 & $1,399<\mathrm{JCR} \geq 0,500$ & 0,73 & 0,618 & 14 & 12 \\
\hline $\begin{array}{l}\text { Revista Brasileira de } \\
\text { Ciência do Solo }\end{array}$ & $\begin{array}{l}\text { Zootecnia / Recursos } \\
\text { Pesqueiros }\end{array}$ & B1 & $1,399<\mathrm{JCR} \geq 0,500$ & 0,72 & 1,001 & 29 & 20 \\
\hline $\begin{array}{l}\text { Brazilian Journal of } \\
\text { Biology }\end{array}$ & Ciências Agrárias I & B1 & $0,001 \geq \mathrm{JCR} \leq 1,499$ & 0,68 & 0,436 & 30 & 18 \\
\hline $\begin{array}{l}\text { Revista Ciência } \\
\text { Agronômica }\end{array}$ & Ciências Agrárias I & B1 & $0,001 \geq \mathrm{JCR} \leq 1,499$ & 0,67 & 0,782 & 10 & 13 \\
\hline $\begin{array}{l}\text { Revista Brasileira de } \\
\text { Entomologia }\end{array}$ & Ciências Agrárias I & B1 & $0,001 \geq \mathrm{JCR} \leq 1,499$ & 0,67 & 0,446 & 13 & 15 \\
\hline $\begin{array}{l}\text { Acta Scientiarum - } \\
\text { Agronomy }\end{array}$ & Ciências Agrárias I & B1 & $0,001 \geq \mathrm{JCR} \leq 1,499$ & 0,63 & 0,65 & 11 & 12 \\
\hline Bioscience Journal & Ciências Agrárias I & B1 & $0,001 \geq \mathrm{JCR} \leq 1,499$ & 0,63 & 0,298 & 6 & 9 \\
\hline $\begin{array}{l}\text { Tropical Plant } \\
\text { Pathology }\end{array}$ & Ciências Agrárias I & B1 & $0,001 \geq \mathrm{JCR} \leq 1,499$ & 0,55 & 0,29 & 8 & 11 \\
\hline $\begin{array}{l}\text { Acta Botânica } \\
\text { Brasílica }\end{array}$ & Ciências Agrárias I & B1 & $0,001 \geq \mathrm{JCR} \leq 1,499$ & 0,55 & 0,403 & 17 & 15 \\
\hline $\begin{array}{l}\text { Crop Breeding and } \\
\text { Applied Biotechnology }\end{array}$ & Ciências Agrárias I & B1 & $0,001 \geq \mathrm{JCR} \leq 1,499$ & 0,5 & 0,4 & 10 & 10 \\
\hline $\begin{array}{l}\text { Revista Brasileira de } \\
\text { Fruticultura }\end{array}$ & $\begin{array}{l}\text { Zootecnia / Recursos } \\
\text { Pesqueiros }\end{array}$ & B1 & $1,399<\mathrm{JCR} \geq 0,500$ & 0,49 & 0,468 & 13 & 8 \\
\hline $\begin{array}{l}\text { Revista Brasileira de } \\
\text { Engenharia Agrícola e } \\
\text { Ambiental }\end{array}$ & Ciências Agrárias I & B1 & $0,001 \geq \mathrm{JCR} \leq 1,499$ & 0,48 & 0,622 & 17 & 18 \\
\hline $\begin{array}{l}\text { Brazilian Archives of } \\
\text { Biology and } \\
\text { Technology }\end{array}$ & $\begin{array}{l}\text { Zootecnia / Recursos } \\
\text { Pesqueiros }\end{array}$ & B1 & $1,399<\mathrm{JCR} \geq 0,500$ & 0,45 & 0,237 & 24 & 16 \\
\hline $\begin{array}{l}\text { Journal of Venomous } \\
\text { Animals and Toxins } \\
\text { Including Tropical } \\
\text { Diseases }\end{array}$ & Ciências Agrárias I & B1 & $0,001 \geq \mathrm{JCR} \leq 1,499$ & 0,43 & 0,182 & 10 & 9 \\
\hline Engenharia Agrícola & Ciências Agrárias I & B1 & $0,001 \geq \mathrm{JCR} \leq 1,499$ & 0,41 & 0,505 & 13 & 12 \\
\hline Ciência Rural & Ciências Agrárias I & B1 & $0,001 \geq \mathrm{JCR} \leq 1,499$ & 0,4 & 0,384 & 17 & 18 \\
\hline Revista Árvore & Ciências Agrárias I & B1 & $0,001 \geq \mathrm{JCR} \leq 1,499$ & 0,4 & 0,486 & 15 & 12 \\
\hline Horticultura Brasileira & Ciências Agrárias I & B1 & $0,001 \geq \mathrm{JCR} \leq 1,499$ & 0,37 & 0,464 & 9 & 12 \\
\hline Cerne & Ciências Agrárias I & B1 & $0,001 \geq \mathrm{JCR} \leq 1,499$ & 0,36 & 0,552 & 7 & 7 \\
\hline Scientia Forestalis & Ciências Agrárias I & B1 & $0,001 \geq \mathrm{JCR} \leq 1,499$ & 0,35 & 0,518 & 14 & 3 \\
\hline $\begin{array}{l}\text { Ciência e Tecnologia } \\
\text { de Alimentos }\end{array}$ & Ciências Agrárias I & B1 & $0,001 \geq \mathrm{JCR} \leq 1,499$ & 0,33 & 0,291 & 15 & 14 \\
\hline $\begin{array}{l}\text { Revista Brasileira de } \\
\text { Ciência Avícola }\end{array}$ & Medicina Veterinária & B1 & $2,266<\mathrm{JCR} \geq 0,756$ & 0,32 & 0,266 & 9 & 9 \\
\hline Revista Caatinga & $\begin{array}{l}\text { Zootecnia / Recursos } \\
\text { Pesqueiros }\end{array}$ & B1 & $1,399<\mathrm{JCR} \geq 0,500$ & 0,31 & 0,37 & 5 & 12 \\
\hline
\end{tabular}




\begin{tabular}{l|l|l|l|r|r|r|r} 
Ciência Florestal & Ciências Agrárias I & $\mathrm{B} 1$ & $0,001 \geq \mathrm{JCR} \leq 1,499$ & 0,24 & 0,504 & 7 & 8 \\
\hline $\begin{array}{l}\text { Iheringia - Serie } \\
\text { Botânica }\end{array}$ & Ciências Agrárias I & $\mathrm{B} 1$ & $0,001 \geq \mathrm{JCR} \leq 1,499$ & 0,24 & 0,157 & 7 & $\begin{array}{r}\text { Não } \\
\text { atribuído }^{1}\end{array}$ \\
\hline $\begin{array}{l}\text { Semina:Ciências } \\
\text { Agrárias }\end{array}$ & Ciências Agrárias I & $\mathrm{B} 1$ & $0,001 \geq \mathrm{JCR} \leq 1,499$ & 0,18 & 0,247 & 8 & 9 \\
\hline $\begin{array}{l}\text { Acta Scientiae } \\
\text { Veterinariae }\end{array}$ & Medicina Veterinária & $\mathrm{B} 1$ & $2,266<\mathrm{JCR} \geq 0,756$ & 0,15 & 0,149 & 3 & 7 \\
\hline $\begin{array}{l}\text { Boletim Centro de } \\
\begin{array}{l}\text { Pesquisa de } \\
\text { Processamento de } \\
\text { Alimentos }\end{array}\end{array}$ & Ciências Agrárias I & $\mathrm{B} 1$ & $0,001 \geq \mathrm{JCR} \leq 1,499$ & - & 0,147 & 3 & \\
\hline $\begin{array}{l}\text { Revista Brasileira de } \\
\text { Medicina Veterinaria }\end{array}$ & Medicina Veterinária & $\mathrm{B} 1$ & $2,266<\mathrm{JCR} \geq 0,756$ & - & 0,125 & 12 & 3 \\
\hline
\end{tabular}

Fonte: Dados da pesquisa (2014).

Conforme observa-se na Tabela 4, 34 títulos são classificados no estrato B1, dentre os 74 títulos desta pesquisa. As revistas B1 que apresentam maiores diferenças entre os índices h são: a) Brazilian Journal of Medical and Biological Research - índice h (Scopus) 62 e índice h5 24; b) Tropical Plant Pathology - índice h (Scopus) 8 e índice h5 11 ec) Revista Brasileira de Medicina Veterinaria - índice h (Scopus) 12 e índice h5 4.

Na Tabela 5, observa-se a distribuição das revistas do estrato B2. Tabela 5 - Comparação dos índices JCR, SJR, índice h Scopus e índice h5 GSM dos periódicos Qualis B2, do corpus desta pesquisa

\begin{tabular}{|c|c|c|c|c|c|c|c|c|}
\hline & 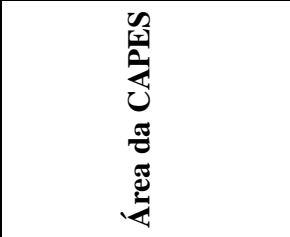 & $\frac{n}{\tilde{\Xi}}$ & 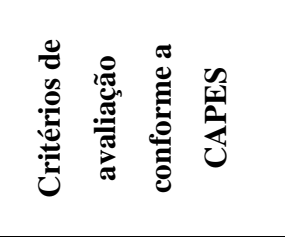 & 气ૈ & $\stackrel{\mathscr{V}}{\vec{\sigma}}$ & 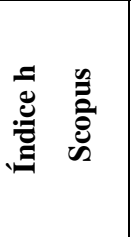 & & 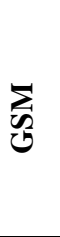 \\
\hline $\begin{array}{l}\text { Brazilian Journal of } \\
\text { Botany }\end{array}$ & Ciências Agrárias I & B2 & 4 Bases indexadoras & 1,385 & 0,262 & 15 & & 12 \\
\hline Biota Neotropica & Ciências Agrárias I & B2 & 4 Bases indexadoras & 0,69 & 0,437 & 12 & & 16 \\
\hline Bragantia & Ciências Agrárias I & B2 & 4 Bases indexadoras & 0.620 & 0,685 & 18 & & 12 \\
\hline $\begin{array}{l}\text { Boletim do Instituto de } \\
\text { Pesca }\end{array}$ & Medicina Veterinária & B2 & $\begin{array}{l}\text { JCR }<0,756 \text { ou ser } \\
\text { indexado em } 4 \text { bases }\end{array}$ & 0,342 & 0,288 & 5 & & 5 \\
\hline Acta Amazônica & Ciências Agrárias I & B2 & 4 Bases indexadoras & - & 0,319 & 13 & & 11 \\
\hline $\begin{array}{l}\text { Acta Scientiarum - } \\
\text { Biological Sciences }\end{array}$ & Ciências Agrárias I & B2 & 4 Bases indexadoras & - & 0,211 & 13 & & 10 \\
\hline $\begin{array}{l}\text { Brazilian Journal of } \\
\text { Plant Physiology }\end{array}$ & Ciências Agrárias I & B2 & 4 Bases indexadoras & - & 0,243 & 30 & & 10 \\
\hline Coffee Science & Ciências Agrárias I & $\mathrm{B} 2$ & 4 Bases indexadoras & - & 0,294 & 4 & & 5 \\
\hline Comunicata Scientiae & Ciências Agrárias I & $\mathrm{B} 2$ & 4 Bases indexadoras & - & 0,174 & 3 & & 5 \\
\hline Floresta & Ciências Agrárias I & $\mathrm{B} 2$ & 4 Bases indexadoras & - & 0,247 & 3 & & 2 \\
\hline Floresta e Ambiente & Ciências Agrárias I & $\mathrm{B} 2$ & 4 Bases indexadoras & - & 0,163 & 2 & & 2 \\
\hline
\end{tabular}

1 Em relação ao índice h5 do GSM, 5 revistas deste estudo não são classificadas entre as 100 revistas consideradas como as melhores por essa ferramenta. São elas: a) Iheringia - Serie Botânica; b) PanAmerican Journal of Aquatic Sciences; c) Annual Review of Biomedical Sciences; d) Ciência Animal Brasileira; e e) Phyllomedusa: Journal of Herpetology. 


\begin{tabular}{|c|c|c|c|c|c|c|c|}
\hline $\begin{array}{l}\text { Pesquisa Agropecuária } \\
\text { Tropical }\end{array}$ & Ciências Agrárias I & B2 & 4 Bases indexadoras & - & 0,385 & 5 & 12 \\
\hline $\begin{array}{l}\text { Revista Brasileira de } \\
\text { Ciências Agrárias } \\
\text { (Agrária) }\end{array}$ & Ciências Agrárias I & B2 & 4 Bases indexadoras & - & 0,244 & 4 & 12 \\
\hline $\begin{array}{l}\text { Revista Brasileira de } \\
\text { Sementes }\end{array}$ & Ciências Agrárias I & B2 & 4 Bases indexadoras & - & 0,336 & 13 & 12 \\
\hline $\begin{array}{l}\text { Summa } \\
\text { Phytopathologica }\end{array}$ & Ciências Agrárias I & B2 & 4 Bases indexadoras & - & 0,326 & 5 & 5 \\
\hline Revista Ceres & Ciências Agrárias I & B2 & 4 Bases indexadoras & - & 0,202 & 2 & 9 \\
\hline $\begin{array}{l}\text { Ciência Animal } \\
\text { Brasileira }\end{array}$ & Medicina Veterinária & B2 & $\begin{array}{l}\text { JCR }<0,756 \text { ou ser } \\
\text { indexado em } 4 \text { bases }\end{array}$ & - & 0,14 & 2 & $\begin{array}{r}\text { Não } \\
\text { atribuído }\end{array}$ \\
\hline
\end{tabular}

Fonte: Dados da pesquisa (2014).

Segundo a Tabela 5, 17 títulos estão concentrados no estrato B2 e dessas, somente quatro estão indexadas na WoS, o restante está somente na Scopus. São elas: a) Brazilian Journal of Botany; b) Biota Neotropica; c) Bragantia; e d) Boletim do Instituto de Pesca.

Segundo dados da tabela 5, destaca-se o caso das revistas Brazilian Journal of Botany, Biota Neotropica e Bragantia, que estão classificadas no estrato B2, mas conforme as exigências da área e seus respectivos fatores de impacto no JCR, deveriam estar inseridas no estrato B1. As revistas que apresentam maiores diferenças entre os índices h são: a) Brazilian Journal of Plant Physiology - índice h (Scopus) 30 e índice h5 10; b) Pesquisa Agropecuária Tropical - índice h (Scopus) 5 e índice h5 12; c) Revista Brasileira de Ciências Agrárias (Agrária) - índice h (Scopus) 4 e índice h5 12; e d) Revista Ceres - índice h (Scopus) 2 e índice h5 9;

Do total de revistas da área foi identificado o percentual que não está em conformidade com o Qualis apontado pelo documento de área, conforme pode-se observar na Tabela 6.

Tabela 6- Relação da quantidade de periódicos do corpus desta pesquisa, que seguem ou não as exigências do JCR para serem classificados no Qualis

\begin{tabular}{l|r|r|r|r|r|r|r|c}
\hline & A2 & B1 & B2 & B3 & B4 & B5 & Total & \% \\
\hline \hline $\begin{array}{l}\text { Qualis dentro do JCR } \\
\text { exigido }\end{array}$ & - & 27 & 1 & - & - & - & $\mathbf{2 8}$ & $\mathbf{3 7 , 8 \%}$ \\
\hline $\begin{array}{l}\text { Qualis abaixo do } \\
\text { JCR exigido }\end{array}$ & - & - & - & - & 1 & 1 & $\mathbf{2}$ & $\mathbf{2 , 7 \%}$ \\
\hline $\begin{array}{l}\text { Qualis acima do JCR } \\
\text { exigido }\end{array}$ & 6 & 5 & - & - & - & - & $\mathbf{1 1}$ & $\mathbf{1 4 , 9 \%}$ \\
\hline $\begin{array}{l}\text { Bases indexadoras } \\
\text { Não estão na WoS }\end{array}$ & - & - & 3 & - & - & - & $\mathbf{3}$ & $\mathbf{4 , 1 \%}$ \\
\hline Total & $\mathbf{6}$ & $\mathbf{3 4}$ & $\mathbf{1 7}$ & $\mathbf{7}$ & $\mathbf{4}$ & $\mathbf{6}$ & $\mathbf{7 4}$ & $\mathbf{1 0 0 , 0 \%}$ \\
\hline
\end{tabular}

Fonte: Dados da pesquisa (2014). 
Conforme pode-se observar na Tabela 6, do total de 74 revistas, 40,5\% (30) títulos não estão na WoS. Das 41 revistas que estão indexadas na WoS, $37,8 \%$ (28) apresentam o estrato Qualis de acordo com o JCR que as áreas da grande área das Ciências Agrárias, exigem. Enquanto que $14,9 \%$ (11) das revistas possuem Qualis acima do JCR que as revistas apresentam. No caso, o indicador JCR desses títulos, não classificam as revistas nos extratos que estão registradas, essas revistas estariam sim classificadas em um estrato abaixo do que estão. E 2,7\% (2) revistas possuem fator de impacto JCR que as classificaria em um estrato Qualis, acima do que estão registradas.

Trzesniak, (2006a) explica que muitas áreas da CAPES baseiam o seu Qualis exclusivamente no JCR da WoS. O que é discutido também por Silva (2010) ao comentar que metade das áreas da pós-graduação usam o fator de impacto JCR, como sendo único critério para avaliar a produção científica de pós-graduandos e seus orientadores. Com isso muitos periódicos científicos brasileiros podem ser classificados abaixo dos níveis adequados e o que os tornaria pouco atrativos para a submissão de artigos de qualidade.

Silva (2010) avalia como injusto o uso exclusivo do JCR para a avaliação de mérito científico, sendo que esta métrica mede imperfeitamente a qualidade dos periódicos, mas não a qualidade de cada artigo ali publicado. O autor aponta que contar o número de citações por artigo pode sim, ser usado como forma de avaliar a qualidade. Dessa forma, voltamos ao efeito Mateus de Merton (2013), sendo que os autores mais antigos teriam mais citações que os novatos e assim apresentariam melhores índices. Embora muitas vezes, essas áreas exijam, nem sempre levam em consideração integralmente o fator de impacto JCR para classificar as suas revistas. Como foi identificado nesta pesquisa por $14,9 \%$ das revistas que possuem JCR abaixo do exigido para ser Qualis A2 e B1.

O fato de algumas revistas desta pesquisa apresentarem diferenças quando comparadas com os índices h da Scopus e do h5 do GSM, se explica pelo fato, que o índice h das revistas da Scopus utiliza o intervalo de tempo de três anos e o h5 do GSM utiliza o intervalo de cinco anos, que abrange mais fascículos e assim mais citações, elevando o índice h5 dos títulos, por apresentar uma cobertura temporal mais alta que a outra. Entretanto, mesmo que as revistas da Scopus apresentem uma cobertura temporal mais curta, elas podem sim, receber mais citações que no GSM.

$\mathrm{Na}$ Tabela 7 pode-se observar a distribuição do idioma dos artigos aceitos pelas revistas das Ciências Agrárias. A informação sobre o idioma dos artigos foi localizada nas informações para os autores, que constava na página das próprias revistas. 
Tabela 7 - Idioma dos artigos aceitos para publicação dos periódicos do corpus desta pesquisa

\begin{tabular}{l|r|r|r|r|r|c}
\hline & Universidades & Associações & $\begin{array}{r}\text { Institutos de } \\
\text { pesquisa }\end{array}$ & Outras & Total & \% \\
\hline Inglês & 10 & 13 & 3 & 2 & $\mathbf{2 8}$ & $\mathbf{3 7 , 8 \%}$ \\
\hline $\begin{array}{l}\text { Inglês; Português e } \\
\text { Espanhol }\end{array}$ & 13 & 9 & 6 & 1 & $\mathbf{2 9}$ & $\mathbf{3 9 , 2 \%}$ \\
\hline Inglês e português & 14 & 2 & 1 & - & $\mathbf{1 7}$ & $\mathbf{2 3 , 0 \%}$ \\
\hline Total & $\mathbf{3 7}$ & $\mathbf{2 4}$ & $\mathbf{1 0}$ & $\mathbf{3}$ & $\mathbf{7 4}$ & $\mathbf{1 0 0 , 0 \%}$ \\
\hline \multicolumn{1}{c}{$\%$} & $\mathbf{5 0 , 0 \%}$ & $\mathbf{3 2 , 4 \%}$ & $\mathbf{1 3 , 5 \%}$ & $\mathbf{4 , 1 \%}$ & $\mathbf{1 0 0 , 0 \%}$ & \\
\hline
\end{tabular}

Fonte: Dados da pesquisa (2014).

Em relação aos idiomas dos artigos aceitos para publicação, 28 $(37,8 \%)$ revistas aceitam trabalhos somente em inglês, $29(39,2 \%)$ revistas aceitam tanto o idioma em inglês, português e espanhol e 17 (23\%) revistas aceitam somente o inglês e português, o que demonstra que as revistas das Ciências Agrárias que compõem o corpus desta pesquisa, dão ênfase na publicação dos títulos em língua inglesa, com o intuito de obter visibilidade internacional.

$\mathrm{Na}$ Tabela 8, é possível observar a periodicidade das revistas que compõem a pesquisa, considerando que a periodicidade indica a movimentação do diálogo da área e do trabalho editorial envolvido no processo. Pode-se medir a vitalidade da área também pelo número de fascículos dos títulos.

Tabela 8 - Periodicidade dos periódicos do corpus desta pesquisa

\begin{tabular}{l|r|r|r|r|r|r|r|r}
\hline $\begin{array}{c}\text { Números por } \\
\text { ano }\end{array}$ & $\mathbf{1}$ & $\mathbf{2}$ & $\mathbf{3}$ & $\mathbf{4}$ & $\mathbf{6}$ & $\mathbf{1 2}$ & $\begin{array}{c}\text { Total de } \\
\text { periódicos }\end{array}$ & $\begin{array}{c}\text { Total de números } \\
\text { por ano }\end{array}$ \\
\hline \hline Universidades & 1 & 2 & 1 & 22 & 8 & 3 & 37 & 180 \\
\hline Associações & 0 & 0 & 1 & 18 & 4 & 1 & 24 & 111 \\
\hline $\begin{array}{l}\text { Institutos de } \\
\text { Pesquisa }\end{array}$ & 0 & 0 & 0 & 8 & 1 & 1 & 10 & 50 \\
\hline Outras & 0 & 1 & 0 & 2 & 0 & 0 & 3 & 10 \\
\hline Total & $\mathbf{1}$ & $\mathbf{3}$ & $\mathbf{2}$ & $\mathbf{5 0}$ & $\mathbf{1 3}$ & $\mathbf{5}$ & $\mathbf{7 4}$ & $\mathbf{3 5 1}$ \\
\hline
\end{tabular}

Fonte: Dados da pesquisa.

Observa-se que predomina a periodicidade de quatro números ao ano, representando $67,6 \%$ (50) das revistas, enquanto que $17,6 \%$ (13) das revistas publicam seis números ao ano, em terceiro lugar está a periodicidade mensal com $6,8 \%$ (5) dos títulos.

Conforme os dados da Tabela 8, a atividade editorial da área envolve a produção de 351 números por ano. Considerando-se uma média de 12 artigos em cada número, pode-se estimar um total de 4.212 artigos publicados por ano. Trzesniak (2006b, p. 352) complementa ao expor que 
"a proposta de periodicidade e seu cumprimento são itens que integram praticamente todas as avaliações e certamente refletem a eficácia do processo produtivo $[\ldots]^{\prime \prime}$.

Entre as plataformas utilizadas $43,2 \%$ (32) das revistas utilizam a plataforma OJS para a gestão editorial de suas revistas, destas, 27 revistas estão concentradas nas universidades. Em segundo lugar, está a SciELO com 31,1\% (23) das revistas que, ao mesmo tempo em que tem estrutura sofisticada de visibilidade do conteúdo, também oferece a gestão das mesmas. A plataforma própria realiza a gestão de $21,6 \%$ (16) das revistas. Em seguida, a Springer faz a gestão de três revistas. a) Brazilian Journal of Botany: indexada pela SciELO até 2013; b) Neotropical Entomology: indexada pela SciELO até 2011; c) Tropical Plant Pathology: indexada pela SciELO até 2014.

Das 32 revistas que o OJS realiza a gestão, 10 são distribuídas também pela SciELO e cinco pela plataforma própria. De um total de 74 revistas, a SciELO realiza a gestão de 23 revistas, entretanto, também oferece a distribuição de outras revistas que não são gestionadas por ela, com um total de 44 revistas. A plataforma própria faz a gestão de 16 revistas e a distribuição de mais 17 revistas que são gestionadas pelo OJS e pelo SciELO.

As principais características das revistas das áreas desta pesquisa são: a) apresentam alta incidência de patrocínio de agências ligadas ao governo federal; b) a maioria dos periódicos da área iniciou entre as décadas de 70 e 80 ; c) mantidas predominantemente por universidades; d) nenhuma revista apresenta Qualis A1, apresentando elevada concentração no estrato $\mathrm{B} 1$, com 34 títulos. As revistas relativas diferenças entre os fatores de impacto da WoS, Scopus e índice $\mathrm{h}$ da Scopus e do GSM; e) o aceite de artigos no idioma inglês aparece em todas as revistas; f) $67,6 \%$ (50) revistas optam por quatro fascículos ao ano; g) a SciELO e o OJS são as plataformas mais utilizadas para a gestão e indexação dos títulos; h) 77\% (57) revistas adotam o DOI como forma de preservar o link para o acesso aos seus artigos.

\subsection{Modelos de financiamento das revistas da área das Ciências Agrárias}

Do total de 74 revistas desta pesquisa, 74\% (55) recebem patrocínio de alguma agência ou Fundação de fomento nacional. a) 46 revistas: CNPQ; b) 43 revistas: CAPES; c) 22 revistas: MEC; d) 20 revistas: MCTI; e) 2 revistas: FAPERGS; f) 8 revistas: FAPEMIG; g) 8 revistas: FAPESP; h) 7 revistas: Fundação Araucária; i) 2 revistas: FAPERJ; e j) 3 revistas são mantidas pela Springer ${ }^{2}$.

Algumas revistas recebem patrocínio em conjunto de mais de um órgão. Essas informações foram localizadas no site da própria revista.

\footnotetext{
${ }^{2}$ Antes de migrarem para a Springer, essas revistas eram patrocinadas por: a) Brazilian Journal of Botany: CNPq; CAPES; MEC; MCTI; Governo Federal; e FAPESP, criada em 1978; b) Neotropical Entomology: CNPq; CAPES; MEC; MCTI e Sociedade Entomológica do Brasil (SEB), revista criada em 2003; e c) Tropical Plant Pathology: CNPq; CAPES e FAPEMIG, criada em 1976.
} 
Para as outras 19 revistas que não foi possível localizar essa informação: 16 revistas pertencem a universidades, uma pertence à associação, uma pertence a instituto de pesquisa e uma pertence a outras.

É possível observar que as revistas da grande área das Ciências Agrárias no Brasil, são financiadas predominantemente com recursos públicos federais e estão ligadas principalmente às universidades. Tal fato é observado também por Swan (2008) ao constatar que a maioria das pesquisas geradas nas universidades e institutos de pesquisa no mundo todo é subsidiada com recursos públicos, no caso brasileiro os fundos públicos financiam também as revistas. Enquanto que para o caso dos países chamados centrais, quem mantém as revistas são as editoras comerciais.

Do total de $74 \%$ das revistas que recebem patrocínio, 32\% (24) apresentam simultaneamente patrocínio e cobrança de alguma taxa para o processamento dos artigos. As taxas de processamento de artigos ou Article Processing Charge (APC), são os valores cobrados aos autores ou instituições para subsidiar os custos das revistas de acesso aberto. Desse modo, o produto final é livre em texto completo para os leitores (BJÖRK; HEDLUND, 2009; CROW, 2009). As APCs são baseadas na premissa de que os autores e suas instituições são beneficiários diretos da publicação dos artigos em uma revista científica (CROW, 2009).

Na Tabela 9, está a relação das revistas que recebem patrocínio e também cobram alguma taxa para processar os artigos.

Tabela 9 - Distribuição do patrocínio pelas taxas de processamento dos periódicos do corpus desta pesquisa

\begin{tabular}{|c|c|c|c|c|}
\hline 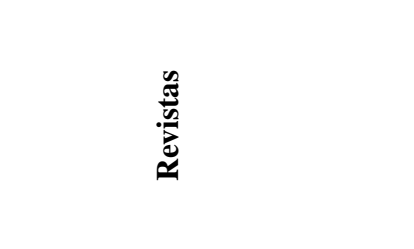 & 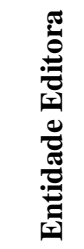 & 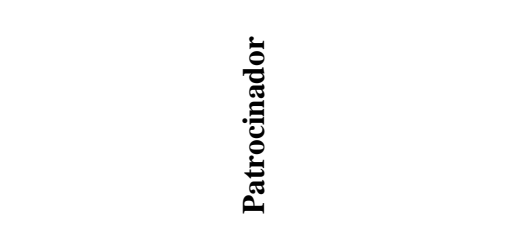 & 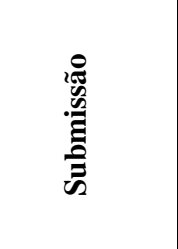 & 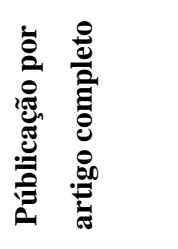 \\
\hline $\begin{array}{l}\text { Arquivo Brasileiro de Medicina } \\
\text { Veterinária e Zootecnia* }\end{array}$ & Uni. & $\begin{array}{l}\text { CNPq; CAPES; MEC; MCTI; Governo } \\
\text { Federal; FAPEMIG }\end{array}$ & - & $\mathrm{R} \$ 864,00$ \\
\hline Bragantia* & Ins. & $\begin{array}{l}\text { CNPq; CAPES; MEC; MCTI; Governo } \\
\text { Federal }\end{array}$ & - & $\mathrm{R} \$ 450,00$ \\
\hline $\begin{array}{l}\text { Brazilian Journal of Medical } \\
\text { and Biological Research }\end{array}$ & Ass. & CNPq; CAPES; MEC; MCTI; FAPESP & - & $\mathrm{R} \$ 2.200,00$ \\
\hline Ciência e Agrotecnologia* & Uni. & CNPq; CAPES; FAPEMIG & $\mathrm{R} \$ 96,00$ & $\mathrm{R} \$ 324,00$ \\
\hline $\begin{array}{l}\text { Ciência e Tecnologia de } \\
\text { Alimentos }\end{array}$ & Ass. & $\begin{array}{l}\text { CNPq; CAPES; MEC; MCTI; Governo } \\
\text { Federal; FAPESP }\end{array}$ & - & $\mathrm{R} \$ 528,00$ \\
\hline Ciência Florestal & Uni. & CNPq; CAPES & $\mathrm{R} \$ 50,00$ & $\mathrm{R} \$ 250,00$ \\
\hline Ciência Rural* & Uni. & CNPq; CAPES; FAPERGS & $\mathrm{R} \$ 60,00$ & $\mathrm{R} \$ 765,00$ \\
\hline Engenharia Agrícola & Ass. & CNPq; CAPES & $\mathrm{R} \$ 300,00$ & - \\
\hline Floresta* & Uni. & CNPq; CAPES; Fundação Araucária & $\mathrm{R} \$ 50,00$ & $\mathrm{R} \$ 180,00$ \\
\hline $\begin{array}{l}\text { Genetics and Molecular } \\
\text { Biology }\end{array}$ & Ass. & CNPq; CAPES; MEC; MCTI; FAPESP & - & $\mathrm{R} \$ 1.200,00$ \\
\hline
\end{tabular}




\begin{tabular}{|c|c|c|c|c|}
\hline Horticultura Brasileira* & Ass. & CNPq; CAPES; MEC; MCTI; FINEP & $\mathrm{R} \$ \quad 444,00$ & $\mathrm{R} \$ 648,00$ \\
\hline $\begin{array}{l}\text { Journal of Venomous Animals } \\
\text { and Toxins Including Tropical } \\
\text { Diseases }\end{array}$ & Uni. & $\begin{array}{l}\text { CNPq; CAPES; MEC; MCTI; Governo } \\
\text { Federal }\end{array}$ & - & $\mathrm{R} \$ 4.656,00$ \\
\hline Neotropical Entomology* & Ass. & $\mathrm{CNPq}$ & - & $\mathrm{R} \$ 777,60$ \\
\hline $\begin{array}{l}\text { Revista Brasileira de Ciência } \\
\text { Avícola* }\end{array}$ & Outras & $\begin{array}{l}\text { CNPq; CAPES; MEC; MCTI; } \\
\text { Fundação APINCO de Ciência e } \\
\text { Tecnologia Avícolas (FACTA) }\end{array}$ & - & $\mathrm{R} \$ 1.080,00$ \\
\hline $\begin{array}{l}\text { Revista Brasileira de Ciência } \\
\text { do Solo* }\end{array}$ & Ass. & $\begin{array}{l}\text { CNPq; CAPES; FAPEMIG; Sociedade } \\
\text { Brasileira de Ciência do Solo (SBCS) }\end{array}$ & - & $\mathrm{R} \$ 450,00$ \\
\hline $\begin{array}{l}\text { Revista Brasileira de } \\
\text { Engenharia Agrícola e } \\
\text { Ambiental }\end{array}$ & Uni. & $\begin{array}{l}\text { CNPq; CAPES; Asociación } \\
\text { Latinoamericano y Del Caribe de } \\
\text { Ingeniería Agrícola (ALIA) }\end{array}$ & $\mathrm{R} \$ 120,00$ & - \\
\hline $\begin{array}{l}\text { Revista Brasileira de } \\
\text { Entomologia* }\end{array}$ & Ass. & $\begin{array}{l}\text { CNPq; CAPES; MEC; MCTI; Governo } \\
\text { Federal; Fundação Araucária; Governo } \\
\text { do Paraná; Secretaria da Ciência, } \\
\text { Tecnologia e Ensino Superior (SETI) }\end{array}$ & - & $\mathrm{R} \$ 450,00$ \\
\hline $\begin{array}{l}\text { Revista Brasileira de } \\
\text { Fruticultura }\end{array}$ & Ass. & $\begin{array}{l}\text { CNPq; CAPES; FAPESP; Sociedade } \\
\text { Brasileira de Fruticultura (SBF) }\end{array}$ & $\mathrm{R} \$ 100,00$ & $\mathrm{R} \$ 250,00$ \\
\hline $\begin{array}{l}\text { Revista Brasileira de } \\
\text { Parasitologia Veterinária }\end{array}$ & Uni. & $\begin{array}{l}\text { CNPq; CAPES; FAPESP; Conselho } \\
\text { Regional de Medicina Veterinária do } \\
\text { Estado de São Paulo (CRMV) }\end{array}$ & - & $\mathrm{R} \$ 500,00$ \\
\hline $\begin{array}{l}\text { Revista Brasileira de } \\
\text { Sementes* }\end{array}$ & Ass. & CNPq; CAPES; FAPEMIG & - & $\mathrm{R} \$ 540,00$ \\
\hline Revista Ceres* & Uni. & CNPq; CAPES; FAPEMIG & - & $\mathrm{R} \$ 2.419,20$ \\
\hline Revista Ciência Agronômica* & Uni. & CNPq; CAPES & $\mathrm{R} \$ 80,00$ & $\mathrm{R} \$ 315,00$ \\
\hline Scientia Agrícola* & Uni. & $\begin{array}{l}\text { CNPq; CAPES; MEC; MCTI; Governo } \\
\text { Federal }\end{array}$ & - & $\mathrm{R} \$ 1.296,00$ \\
\hline Summa Phytopathologica & Ass. & $\begin{array}{l}\text { CNPq; CAPES; MEC; MCTI; Governo } \\
\text { Federal }\end{array}$ & $\mathrm{R} \$ 100,00$ & - \\
\hline
\end{tabular}

Fonte: Dados da pesquisa.

Os dados referentes às taxas de processamento e às assinaturas foram coletados na página de cada uma das revistas.

Do total de 74 títulos, $56,8 \%$ (42) das revistas seguem a via dourada, cobrando algum tipo de taxa de processamento e $43,2 \%$ (32) disponibilizam suas revistas sem nenhum custo para leitores e autores, seguindo a via platina de publicação, onde a entidade editora é integralmente responsável pelos custos associados ao periódico. Verificase que as entidades que mais cobram taxas são exatamente as que mais revistas mantêm, com concentração especial nas universidades e associações.

Os valores ${ }^{3}$ de submissão variam de US\$ 8,91 à US\$ 132,01 , enquanto que os custos para publicação variam de US\$14,27 à US\$

\footnotetext{
${ }^{3}$ Utilizado o câmbio US\$1 = R \$3.36
} 
1.384,40. Das revistas que cobram para publicar os artigos completos, $14,9 \%$ (11) aceitam artigos somente no idioma inglês.

Dos periódicos estudados, $100 \%$ deles estão em formato online, o que deixa evidente a adoção da migração dos títulos impressos para a adoção total do formato eletrônico. Do total de revistas desta pesquisa, 29,3\% (22) ainda aceitam assinatura para a versão impressa, como pode ser observado no Apêndice D. O valor mais alto encontrado para a subscrição é da revista Brazilian Journal of Biology, editada pelo Instituto Internacional de Ecologia (São Paulo), que cobra $\mathrm{R} \$ 600,00$ reais por ano, para a assinatura da sua revista que publica 4 fascículos ao ano.

O principal modelo de negócio adotado pelas revistas das Ciências Agrárias a nível nacional é a via dourada, com 56,8\% (42) das revistas cobrando algum tipo de taxa de processamento, com destaque para as seguintes taxas: por página colorida publicada; por submissão; publicação por página; publicação por artigo completo; e subscrição. Sendo que $43,2 \%$ (32) das revistas seguem a via platina, sem cobrar nenhum custo dos leitores nem autores, utilizando apenas os recursos da instituição editora. O que se pode concluir é que para o caso do Brasil, a via platina funciona graças aos fundos públicos, às universidades, às associações, aos institutos de pesquisa e também à SciELO, que é mantida pela Fapesp.

\section{Conclusão}

Como corpus da pesquisa, obteve-se um total de 74 revistas, todas estão indexadas na Scopus, sendo que destas, 44 também estão indexadas na WoS. Dos títulos estudados 71 estão em acesso aberto, distribuído entre a via platina e a via dourada de publicação, e três títulos em acesso restrito comercial, mantidos pela Springer.

A década de criação que ficou mais em evidência foi entre 1971 e 1980 com 31,1\% (25) das revistas. O que indica a necessidade de tempo para a consolidação dos títulos. Como principais entidades editoriais estão as universidades que mantêm 50\% (37) das revistas e em segundo lugar as Associações com 24 (32,4\%).

Em relação ao Qualis, verifica-se que nenhum título é $A 1$, e no estrato $A 2$, apresenta seis revistas, sendo que a predominância dos títulos está no estrato $\mathrm{B} 1$, com $43,2 \%$ (32) revistas. Do total de revistas do corpus deste estudo, 14,9\% (11) dos títulos possuem Qualis acima do JCR que as revistas apresentam. No caso, o indicador JCR desses títulos, não classificam as revistas nos extratos que estão registradas, essas revistas estariam sim classificadas em um estrato abaixo do que estão. E 2,7\% (2) revistas possuem fator de impacto JCR que classificaria as mesmas, em um estrato Qualis, acima do que estão registradas. Quando comparadas, observou-se também, discordância entre as revistas em relação aos fatores de impacto do JCR, SJR e dos índices h da Scopus e h5 do GSM.

Dos periódicos estudados, 29 (39,2\%) aceitam em conjunto, o idioma inglês, português e espanhol para a publicação de artigos, e 37,8\% (28) dos títulos aceitam somente o idioma inglês. O que mostra o 
significativo interesse da área em aumentar o grau de internacionalização de suas revistas e o número de citações.

A periodicidade mais adotada pelas revistas desta pesquisa é a trimestral, com quatro números ao ano, representando $67,6 \%$ (50) dos títulos que adotam este intervalo. A atividade editorial da grande área das Ciências Agrárias produz 351 volumes por ano em 2014, e aproximadamente 4.000 artigos publicados anualmente, considerando-se uma média de 12 artigos em cada volume.

Em relação à utilização das plataformas de gestão e distribuição das revistas, 43,2\% (32) utilizam a plataforma OJS e desse total, 27 revistas estão concentradas nas universidades. Em segundo lugar, está a SciELO com $31,1 \%$ (23) das revistas que ao mesmo tempo em que distribui também oferece a gestão editorial das mesmas. A plataforma própria realiza a gestão de 21,6\% (16) das revistas. Em relação aos títulos mantidos pela Springer, eles pertencem a associações e antes de migrarem para esta editora comercial, recebiam patrocínio do governo federal e estadual. As três revistas são consideradas de qualidade, recebiam patrocínio e eram mantidas pela SciELO. Aqui cabe uma reflexão acerca do motivo pelo qual mesmo assim, migraram para a Springer, fato que repercute no modelo brasileiro de gestão e publicação científica.

Verifica-se que das 32 revistas que o OJS realiza a gestão, 10 são distribuídas também pela SciELO e cinco pela plataforma própria. De um total de 74 revistas, a SciELO realiza a gestão de 23 revistas, entretanto, também oferece a distribuição de outras revistas que não são gestionadas por ela, com um total de 44 revistas. E das 23 revistas que gestiona, 12 revistas são distribuídas também pelo OJS e pela plataforma própria. A plataforma própria faz a gestão de 16 revistas e a distribuição de mais 17 revistas que são gestionadas pelo OJS e pelo SciELO. A Springer faz a gestão e distribuição de três revistas brasileiras, todas pertencem a associações.

Entre os patrocinadores dessas revistas se destacam o CNPq, CAPES, Governo Federal, Ministério da Educação (MEC), Ministério da Ciência, Tecnologia e Inovação (MCTI) em conjunto com as FAPs de cada Estado, sendo que os estados que mais concentram revistas é São Paulo, com 32,4\% (24), em segundo lugar está o Paraná com 16,2\% (12) títulos e, logo em seguida, Minas Gerais com 13,5\% (10).

Em relação ao modelo de financiamento, 56,8\% (42) das revistas cobram algum tipo de taxa de processamento: publicação colorida por página varia de $\mathrm{R} \$ 80,00$ à $\mathrm{R} \$ 528,00$; submissão por artigo varia de $\mathrm{R} \$$ 30,00 à $\mathrm{R} \$ 444,00$; publicação por página de artigo varia de $\mathrm{R} \$ 20,00$ às $\mathrm{R} \$ 268,00$; e publicação por artigo completo varia de $\mathrm{R} \$ 48,00$ à $\mathrm{R} \$$ $4.656,00$. Enquanto que $29,7 \%$ (32) disponibilizam suas revistas sem nenhum custo e 29,3\% (22) das revistas ainda aceitam assinatura para a versão impressa que os valores variam de $\mathrm{R} \$ 70,00$ à $\mathrm{R} \$ 600,00$. Os títulos que cobram alguma taxa de processamento, são mantidos principalmente pelas universidades e associações.

Fica evidente com esta pesquisa que o acesso aberto no Brasil, para as revistas das Ciências Agrárias, funciona graças aos investimentos 
públicos pela via platina e com cobrança de taxas de processamento dos autores.

\section{Referências}

ABAD-GARCÍA, M. F. Financial aspects of open access journals. Contributions to Science, Barcelona, v. 5, n. 1, p. 107-114, 2009. Disponível em: <http://publicacions.iec.cat/repository/pdf/00000087\%5C00000003.pdf>. Acesso em: 18 jan. 2015.

ABADAL, E. Acceso abierto a la ciència. Barcelona: Editorial UOC, 2012. (Colección El profesional de la información) 51 p. Disponível em: http://diposit.ub.edu/dspace/bitstream/2445/24542/1/262142.pdf>.

Acesso em: 20 ago. 2013.

ABRIZAH. A. et al. LIS journals scientific impact and subject categorization: a comparison between Web of Science and Scopus. Scientometrics, v. 94, n. 2, p. 721-740, 2013a. Disponível em: <DOI 10.1007/s11192-012-0813-7>. Acesso em: 18 jan. 2015.

BJÖRK, B.-C. A model of scientific communication as a global distributed information system. Information Research, v. 12, n. 2, p. 1-47, jan. 2007. Disponível em: <http://www.informationr.net/ir/12-2/paper307.html>. Acesso em: 20 fev. 2015.

BJÖRK, B.-C.; HEDLUND, T. Two scenarios for how scholarly publishers could change their business model to open access. The Journal of Electronic Publishing, Michigan, v. 12, n. 1, p. 1-10, 2009. Disponível em: $<$ http://dx.doi.org/10.3998/3336451.0012.102>. Acesso em: 20 fev. 2015.

BRZEZINSKI, $M$. Power laws in citation distributions: evidence from Scopus. Scientometrics, v. 102, n. 1, p. 213-228, jan. 2015. Disponível em: <http://link.springer.com,/article/10.1007/s11192-014-1524-z>. Acesso em: 10 fev. 2015.

BUAINAIN, A. M. et al. O mundo rural no Brasil do século 21: a formação de um novo padrão agrário e agrícola. Brasília, DF: EMBRAPA, 2014. p. 12. Disponível em: <https://www.EMBRAPA.br/busca-de-publicacoes//publicacao/994073/o-mundo-rural-no-brasil-do-seculo-21-a-formacaode-um-novo-padrao-agrario-e-agricola>. Acesso em: 20 jan. 2015.

CHADEGANI, A. A. et al. A comparison between two main academic literature collections: Web of Science and Scopus Databases. Asian Social Science, v. 9, n. 5, p. 18-26, 2013. Disponível em: <http://arxiv.org/ftp/arxiv/papers/1305/1305.0377.pdf>. Acesso em: 23 nov. 2014.

CONNAWAY, L. S.; POWELL, R. R. Basic research methods for librarians. 5. ed. California: Libraries Unlimited, 2010. 370 p. 
COORDENAÇÃO DE APERFEIÇOAMENTO DE PESSOAL DE NÍVEL SUPERIOR (CAPES). Diretoria de Avaliação QUALIS: concepção e diretrizes básicas. Revista Brasileira de Pós-Graduação, v. 1, n. 1, p. 149-151, 2004. Disponível em: <http://ojs.rbpg.CAPES.gov.br/index.php/rbpg/article/view/31/28>. Acesso em: 20 nov. 2014.

COORDENAÇÃO DE APERFEIÇOAMENTO DE PESSOAL DE NÍVEL SUPERIOR (CAPES). Documento de Área 2013: Ciência e Tecnologia de Alimentos. Brasília, 2013a. Disponível em: <https://drive.google.com/viewerng/viewer?a =v\&pid=sites\&srcid=Y2FwZ XMuZ292LmJyfHRyaWVuYWwtMjAxM3xneDo1NDMzMjg5ODY4NjA2ZjIz>.

Acesso em: 20 jul. 2013.

COORDENAÇÃO DE APERFEIÇOAMENTO DE PESSOAL DE NÍVEL SUPERIOR (CAPES). Documento de Área 2013: Ciências Agrárias I. Brasília, 2013b. Disponível em: $<$ https://drive.google.com/viewerng/viewer?a =v\&pid=sites\&srcid $=Y 2 F w Z$ XMuZ292LmJyfHRyaWVuYWwtMjAxM3xneDo1Yzg1YzcxYTIwYWE5Yzdi>. Acesso em: 20 jul. 2013.

COORDENAÇÃO DE APERFEIÇOAMENTO DE PESSOAL DE NÍVEL SUPERIOR (CAPES). Documento de Área 2013: Medicina Veterinária. Brasília, 2013c. Disponível em: <https://drive.google.com/viewerng/viewer?a=v\&pid=sites\&srcid=Y2FwZ XMuZ292LmJyfHRyaWVuYWwtMjAxM3xneDphYmExMjQyNTI4NjRhMmE>. Acesso em: 20 jul. 2013.

COORDENAÇÃO DE APERFEIÇOAMENTO DE PESSOAL DE NÍVEL SUPERIOR (CAPES). Documento de Área 2013: Zootecnia/Recursos Pesqueiros. Brasília, 2013d. Disponível em: <https://drive.google.com/viewerng/viewer?a = v\&pid=sites\&srcid=Y2FwZ XMuZ292LmJyfHRyaWVuYWwtMjAxM3xneDo2OGUwMDg4ZGEwMjY4ZGQ4 $>$. Acesso em: 20 jul. 2013.

COORDENAÇÃO DE APERFEIÇOAMENTO DE PESSOAL DE NÍVEL SUPERIOR (CAPES). Relatório de gestão do exercício de 2013. Brasília, 2014. Disponível

em: <http://www.CAPES.gov.br/images/stories/download/Contas_Publicas/Rel atorio-de-Gestao-2013.pdf>. Acesso em: 20 dez. 2014.

CORREIA, A. M. R.; MESQUITA, A. Mestrados e doutoramentos. 2. ed. Porto: Vida Econômica, 2013. 318 p.

CRESWELL, J. W. Projeto de pesquisa: métodos qualitativo, quantitativo e misto. 3. Ed. Porto Alegre: ARTMED, 2010. 296 p.

CROW, R. Income models for open access: an overview of current practice. Whashinton, D.C: Scholarly \& Academic Resources Coalition, 2009. 56 p. Disponível em: <http://www.sparc.arl.org/sites/default/files/incomemodels_v1.pdf>. Acesso em: 26 jul. 2014. 
DELGADO-LÓPEZ-CÓZAR, E.; CABEZAS-CLAVIJO, Á. Google Scholar Metrics: an unreliable tool for assessing scientific journals. El Professional de la información, v. 21, n. 4, p. 419-425, mar. 2012. Disponível em $<$ http://elprofesionaldelainformacion.metapress.com/media/2gurm834tjd xqneejmfk/contributions/q/0/3/g/q03gk6v6u5875872.pdf>. Acesso em: 10 jan. 2015.

DELGADO-LÓPEZ-CÓZAR, E.; CABEZAS-CLAVIJO, Á. Ranking journals: could Google Scholar Metrics be an alternative to Journal Citation Reports and SCImago Journal Rank? Learned Publishing, v. 26, n. 2, p. 101-114, jun. 2013. Disponível em <http://dx.doi.org/10.1087/20130206>. Acesso em: 10 jan. 2015.

EMPRESA BRASILEIRA DE PESQUISA AGROPECUÁRIA (EMBRAPA). Quem somos. 2014a. Disponível em: <https://www.EMBRAPA.br/quemsomos>.Acesso em: 2 out. 2014.

FREITAS, M. H. Considerações acerca dos primeiros periódicos científicos brasileiros. Ciência da Informação, Brasília, v. 35, n. 3, p. 54-66, set./dez. 2006. Disponível em: <http://www.scielo.br/pdf/ci/v35n3/v35n3a06>. Acesso em: 20 dez. 2014.

FUNDAÇÃO DE AMPARO À PESQUISA DO ESTADO DE SÃO PAULO (FAPESP). Análise da produção científica a partir de publicações em periódicos especializados. In: FUNDAÇÃO DE AMPARO À PESQUISA DO ESTADO DE SÃO PAULO (FAPESP). Indicadores de ciência tecnologia e inovação em São Paulo. São Paulo: FAPESP, 2010a. cap. 4. p. 4-71. Disponível em: <http://www.FAPESP.br/indicadores/2010/volume1/cap4.pdf>. Acesso em: 20 fev. 2015.

GARFIELD, E. The history and meaning of the journal impact factor. Journal of the American Medical Association, v. 295, n. 1, p. 90-93, 2006. Disponível em: <http://garfield.library.upenn.edu/papers/jamajif2006.pdf>. Acesso em: 15 jan. 2015.

GOOGLE SCHOLAR. Metrics. 2014. Disponível em: $<$ http://scholar.google.com.br/citations?view_op=top_venues\&hl=pt-

BR>. Acesso em: 20 nov. 2014.

GUÉDON, J.-C. In Oldenburg's long shadow: librarians, research scientists, publishers, and the control of scientific publishing. Washington, D.C.: Association of Research Libraries, 2001. p. 1-5. Disponível em: <http://www.arl.org/resources/pubs/mmproceedings/138guedon.shtml>. Acesso em: 20 ago. 2014.

GUÉDON, J.-C. Acesso aberto e divisão entre ciência predominante e ciência periférica. In: FERREIRA, S. M.; TARGINO, M. das G. (Orgs.). Acessibilidade e visibilidade de revistas científicas eletrônicas. São Paulo: Editora São Paulo, 2010. cap. 1. p. 21-78.

LE COADIC, Y.-F. A ciência da informação. 2. ed. Brasília: Briquet de Lemos, 2004. $124 \mathrm{p}$. 
LÓPEZ-ILLESCAS, C.; MOYA-ANEGÓN, F. de; MOED, H. F. Coverage and citation impact of oncological journals in the Web of Science and Scopus. Journal of Informetrics, v. 2, n. 4, p. 304-316, 2008. Disponível em: <http://www.sciencedirect.com/science/article/pii/S175115770800045X> . Acesso em: 15 jan. 2015.

MACIAS-CHAPULA, C. O papel da informetria e da cienciometria e sua perspectiva nacional e internacional. Ciência da Informação, Brasília, v. 27, n. 2, p. 134-140, 1998.

MELERO, R.; ABAD-GARCÍA, M. F. Revistas open access: características, modelos económicos y tendencias. BiD: textos universitaris de Biblioteconomia i Documentació, Barcelona, n. 20, p. 1-17, jun. 2008. Disponível em: <http://bid.ub.edu/20meler2.htm>. Acesso em: 10 fev. 2015.

MENEGHINI, R. Emerging journals. EMBO Reports, v. 13, p. 106-108, 2012b. Disponível em: <2014http://www.ncbi.nlm.nih.gov/pmc/articles/PMC3271339/>. Acesso em: 10 fev.

MENEGHINI, R. Internationalizing a Prestigious Brazilian Scientific Journal. Journal of the Brazilian Chemical Society, v. 25, p. 797-798, 2014. Disponível em: <http://www.crossref.org/iPage?doi=10.5935\%2F01035053.20140081>. Acesso em: 10 fev. 2014.

MERTON, R. K. Ensaios de sociologia da ciência. São Paulo: Editora 34, 2013. 303 p.

MIGUEL, S.; CHINCHILLA-RODRIGUEZ, Z.; MOYA-ANÉGON, F. de. Open Access and Scopus: a new approach to scientific visibility from the standpoint of access. Journal of the American Society for Information Science and Technology, n. 62, p. 1130-1145, jun. 2011.

MUELLER, S. P. M. Produção e financiamento de periódicos científicos de acesso aberto: um estudo da base SciELO. In: POBLACIÓN, D. A. et al. (Orgs.). Dos processos tradicionais às perspectivas alternativas de comunicação. São Paulo: Ateliê Editorial, 2011. cap. 9. p. 201-229.

NETWORK OF COLLABORATION BETWEEN EUROPE AND LATIN AMERICA AND CARIBBEAN COUNTRIES. Necobelac: cursos de formação. 2011. Disponível em: <http://www.iata.csic.es/ bibrem/necobelac/NECOBELAC_OA_PT.pdf> Acesso em: 3 jan. 2015.

PINTO, A. L.; MATIAS, M. Indicadores científicos e as universidades brasileiras. Informação \& Informação, Londrina, v. 16, n. 3, p. 1-18, $2011 . \quad$ Disponível em: <http://www.uel.br/revistas/uel/index.php/informacao/article/view/11498 /10640>. Acesso em: 12 abr. 2012. 
PRICE, D. de S. O desenvolvimento da ciência: análise histórica, filosófica, sociológica e econômica. Rio de Janeiro: Livros Técnicos e Científicos, 1976. $77 \mathrm{p}$.

RODRÍGUEZ-YUNTA, L. Las revistas iberoamericanas en Web of Science y Scopus: visibilidad internacional e indicadores de calidad. In: SEMINARIO HISPANO-MEXICANO DE INVESTIGACIÓN EN BIBLIOTECOLOGÍA Y DOCUMENTACIÓN, 7., 2010, Ciudad de México. Anais... Ciudad de Mexico, 2010. Disponível em: <http://eprints.rclis.org/bitstream/10760/14490/1/LuisRY7Encuentro.pdf $>$. Acesso em: 25 mar. 2014.

SCHWARTZMAN, S. Um espaço para a ciência: a formação da comunidade cientifica no Brasil. Brasília, DF: CNPq/MCT, 2001. 276 p. Disponível em: <http://www.schwartzman.org.br/simon/spacept/espaco.htm>. Acesso em: 11 fev. 2014.

SILVA, M. R. e. Qualis 2011-2013 - os três erres. Clinics, v. 65, n. 10, p. 935-936, 2010. Disponível em: <http://producao.usp.br/handle/BDPI/8537>. Acesso em: 18 jan. 2015.

SILVA, J. F. M. da; RAMOS, L. M. S. V. C. R.; NORONHA, D. P. Base de dados. In: POBLACIÓN, D. A.; WITTER, G. P.; SILVA, J. F. M.o da. Comunicação e produção científica: contexto, indicadores, avaliação. São paulo: Angellara, 2006. cap. 10. p. 263-285.

SILVA, J. F. M. da; SANTOS, M. dos; PRAZERES, A. P. P. dos. Incubadora de revistas científicas. In: POBLACIÓN, D. A. et al. (Org.). Dos processos tradicionais às perspectivas alternativas de comunicação. São Paulo: Ateliê Editorial, 2011. cap. 3. p. 69-90.

SOLOMON, D. J.; BJÖRK, B.-C. A study of open access journals using article processing charges. Journal of the American Society for Information Science and Technology, v. 63, n. 8, p. 1485-1495, 2012b. Disponível em: <onlinelibrary.wiley.com/doi/10.1002/asi.22673/abstract>. Acesso em: 25 set. 2014.

TRZESNIAK, P. As dimensões da qualidade dos periódicos científicos e sua presença em um instrumento da área da educação. Revista Brasileira de Educação, Rio de Janeiro, v. 11, n. 32, p. 346-361, 2006 a.

TRZESNIAK, P. A avaliação de revistas eletrônicas para órgãos de fomento: respondendo ao desafio. In: CONFERÊNCIA IBEROAMERICANA DE PUBLICAÇÕES ELETRÔNICAS NO CONTEXTO DA COMUNICAÇÃO CIENTÍFICA, 1., 2006, Brasília. Anais... Brasília: Universidade de Brasília, 2006b. $\quad$ p. 1-8. Disponível em: <https://www.academia.edu/872628/A_avalia\%C3\%A7\%C3\%A30_de_re vistas_eletr\%C3\%B4nicas_para_\%C3\%B3rg\%C3\%A3os_de_fomento_res pondendo_ao_desafio?login=alineoliveira090@gmail.com\&email_was_take $\mathrm{n}=$ true $>$. Acesso em: 17 nov. 2012. 
VAUGHAN, L. Statistical methods for the information professional: a practical, painless approach to understanding, using and interpreting statistics. 4. ed. New Jersey: Information Today, Inc., 2008. 209 p.

WEITZEL, S. da R. Fluxo da informação científica. In: POBLACIÓN, D. A.; WITTER, G. P.; SILVA, J. F. M. da. Comunicação e produção científica: contexto, indicadores, avaliação. São Paulo: Angellara, 2006. cap. 3. p. 81-113.

WILLINSKY, J. The nine flavours of open access scholarly publishing. Journal of Postgraduate Medicine, v. 49, n. 3, p. 263-267, 2003. Disponível em: <http://www.jpgmonline.com/article.asp?issn=0022-

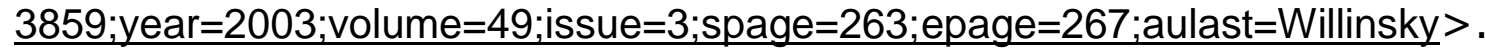

Acesso em: 25 dez. 2014.

WITTER, G. P. Apresentação: revistas científicas: da incubação à visibilidade. In: POBLACIÓN, D. A. et al. (Org.). Revistas científicas: dos processos tradicionais às perspectivas alternativas de comunicação. São Paulo: Ateliê Editorial, 2011. p. 11-22. 